\title{
LAS OPERACIONES DE BOLSA
}

\section{Por HUGo PIAGgIO}

1. - Bajo el título de operaciones de Bolsa pueden incluirse una larga serie de actos económicos, que tengan por lo menos para uno de los contratantes, el fin directo $o$ indirecto de obtener ventajas de las variaciones del curso de los valores o de los precios de las mercaderias en relación al tiempo.

Estas operaciones en la práctica se confunden frecuentemente con las operaciones ordinarias del comercio, que se refieren principalmente a la distribución de los bienes económicos en el espacio.

Ellas limitan, además con las operaciones bancarias, en cuanto los banqueros, las instituciones de crédito mobiliario y los sindicatos de banqueros intervienen en la emisión de títulos y en su colocación, así como en las operaciones de especulación sobre títulos, divisas, monedas, metales preciosos y ciertas mercaderías.

II. - La práctica y la teoría han elaborado desde hace mucho tiempo diversas clasificaciones de las operaciones de Bolsa.

La más genérica de ellas es aquella que después se reproduce en otras clasificaciones especificas, y que se refiere al objeto de las operaciones mismas, de las que resulta que tenemos operaciones sobre valores públicos y privados, hetras, monedas, metales preciosos y productos.

Con respecto a los valores públicos y privados pueden hacerse emisiones públicas y privadas, operaciones de conversión y de amortización, publicas y privadas: operaciones de compraventa y operaciones de prenda: descuento.

Sobre las letras tenemos operaciones de emisión, compraventa y

Y sobre las monedas, metales preciosos y productos, operaciones. de compraventa, prenda y anticipación.

III.-OPERACIONES DE EMISION. - Como hemos dicho pueden referirse a los valores y a las letras.

Emisión de Valores. - Si se atiende al curso de la emisión los valores pueden lanzarse a la par y sobre o bajo la par.

$\mathrm{Si}_{i}$ se toma en cuenta el rendimiento, los valores pueden producir un interés fijo, al menos nominalmente, como sucede en los empréstitos públicos: bonos del tesoro; 0 en los prestamos privados: obligaciones $y$ bonos; o pueden producir un interés variable, como sucede en las acció 
nes de la mayor parte de las empresas.

Algunas veces se unen a la renta fija, dividendos eventuales, como premios o bonificaciones.

Si se toma en cuenta el modo de la emisión, los valores pueden emitirse, directamente por el emitente, o por intermedio de terceros que frecuentemente son sindicatos de banqueros; lo que puede ocurrir mediante la adquisición de todos los títulos, para venderlos por pequeñas partidas o para conservarlos, mediante una garantía de su colocación, o corriendo con la colocación, pero quedando los , riesgos de ella por cuenta del emitente, ganando unicamente la diferencia entre el precio pagado al emitente y el desembolsado por el público.

Si se parte del punto de vista de la forma de la emisión se tienen emisiones simultaneas $o$ por introducción, como dicen los alemanes y por ruscripción pública, 'sistema muy usado en los empréstitos públicos, cediendo los títulos a un precio muy inferior al nominal, reclamando tan sólo una cantidad a cuenta y pagando hasta el interés íntegro con el fin de tener una suscripción múltiple; imponiendo algunas veces por un cierto tiempo lo que los alemanes llaman la cadena, es decir, la obligación de no revender, para no deprimir el curso de los valores; impidiendo las adquisiciones con fines especulativos, etc.

$\mathrm{Si}$ se atiende a los momentos por los que pasa la emisión se pue. de distinguir el momento de la creación; después, si intervienen intermediarios, un momento intermedio $y$ en fin el de la colocación, que comprende todas las operaciones que tienen por objeto colocar el título, sin deprimir su curso, sosteniendo la emisión como dicen los ingleses.

Las operaciones de colocación pueden tener por objeto títulos aún no emitidos.- Estos contratos se hacen tanto en Nueva York como en París fuera del mercado oficial.- Ellas pueden reducirse en su importe, si asi lo exige el resultado.

Si las operaciones de colocación tienen por objeto títulos ya emitidos, pero aun no colocados, la operación se reduce a una simple com. pra venta.

IV.- Emisión de letras.- Estas emisiones pueden referirse a efectos pagaderos en el país o pagaderos en el extranjero; pueden referirse a cheques o a efectos de corto o largo plazo; pueden referirse a éfectos de comercio como dicen los ingleses o a efectós creados por la especulación.

V.- Régimen jurídico.- Hemos visto que los valores en general y las letras en especial, sufren un diverso tratamiento jurídico en el tiempo $y$ en el espacio y un diverso tratamiento fiscal también en el espacio y en el tiempo. - Una mayor uniformidad por lo menos, en el espacio sin duda alguna que favorecería.- Sobre todo, sería deseable para los títulos que circulan de un país a otro como las divisas. - Este punto ha sido materia ya de diversas conferencias que se han propuesto la unificación del régimen jurídico fiscal de las letras internacionales, pero sin que los resultados conseguidos, se hayan aproximado a las aspiraciones de los teóricos o de los prácticos.

VI.- Datos estadísticos sobre las emisiones.- Los datos sobre las emisionea de los títulos públicos y privados y de las mismas letras tienen un gran valor, aún si se les considera como simoles indicios.

Ellas tienen un grado diverso de seguridad que es notorio para 
los títulos públicos, menor para los valores privados y muy escasos para las letras.

No es éste el caso de reproducir cifras, pues todos sabemos, como la guerra ha inflado las emisiones de valores públicos y privados,

VII.- Conversión de títulos de la deuda pública. Las operaciones de conversión se refieren principalmente a los títulos de la deuda pública.

Se les puede convertir en otros títulos de especie diversa, por ejemplo de redimibles en perpetuos; o en títulos que devengan un menor interés, o en otros títulos que devengan un interés mayor, como podría suceder y como se ha propuesto, en períodos en los cuales los precios suben y sube el interés, es decir, 'el precio del servicio del capital y el curso de los títulos consolidados, aún el de los más sólidos baja, como sucedió durante la anterior guerra.- En esté último caso, se podría hablar con más propiedad de verdaderas conversiones al revés.

Las conversiones de títulos en otros de diversa especie pueden ser forzadas o libres, según que se consienta a los acreedores continuar o no en las condiciones en las cuales se encuentran.

Las conversiones de títulos en otros a interés menor, pueden ser forzosas directas, si traen una disminución abierta y franca del tipo de interés; indirectas, si lo dejan intacto, pero lo reducen de hecho, imponiendo un tributo a los poseedores nacionales. - Pueden ser opcionales si consienten en el reembolso a quien no quiera sufrir la disminución del interés; y pueden llevarse a efecto directamente por el estado, que con una deuda flotante, se procura los fondos del rembolso; o por intermedio de un sindicato de banqueros nacionales o internacionales.

VIII Amortización de los títulos de la deuda pública y privada.-

Las operaciones de amortización se refieren principalmente a títulos de la deuda pública, a las obligaciones de los municipios, de las provincias, de las sociedades anónimas etc.

El estado puede disminuir su deuda pública, amortizando sus tituJos, sea adquiriéndolos directamente en el mercado y destruyéndolos co. mo se hizo por ejemplo en los Estados Unidos y en otros paípes, o instituyendo cajas de amortización, o gozando los beneficios de cajas de amortización privadas como por ejemplo en el consorcio italiano.

Estas cajas se crearon basandose en una erronea teoría sobre la potencia mágica de los intereses compuestos, que los resultados se han encargado de demostrar.

EI estado, los municipios y aún las sociedades anónimas para la amortización de sus bonos recurren a veces al reembolso mediante la suer. te, pagando a veces premios, siguiendo un plan trazado que incluye el pago también de los intereses del préstamo, por todo el tiempo de su duración.

IX._ Operaciones de compraventa.- Es particularmente en ellas, es decir en su variedad y combinaciones más características y delicadas que se desarrolla la actividad de las bolsas.

En lo que se refiere al objeto, sabemos ya, que las operaciones de compraventa pueden referirse a valores, letras, monedas, metales preciosos $y$ productos.

En cuanto al momento de la ejecución, las operaciones de compra venta pueden ser, al contado, a plazos o mixtas, especialmente para los 
productos.

En cualquiera de estas formas se pueden realizar operaciones al arbitraje comercial.

X.- Caracteres comunes - En todas estas operaciones pueden notarse carácteres comunes sea en lo que se refiere a las órdenes acostumbradas que se trasmiten a los intermediarios, o a la uniformidad de la cantidad y calidad contratada, con excepción para los contràtos no especulativos, por los vencimientos típicos, por los usos comunes y en fin por la confianza más o menos fundada que los inspira.

XI. - Operaciones al contado. - Son aquellas en las que la ejecución no es diferida ó lo es por muy poco tiempo o lo es por abuso.

En las grandes bolsas no son ciertamente las operaciones más importantes ni en querer dar lugar a una dísciplina particulax. ;

Las operaciones de compra venta al contado, son llamadas por los franceses "mercado al contado" y "negocios por caja" por los ingleees y los alemanes.

Estas operaciones se distinguen segun el objeto y seguin el fin que puede ser especulativo y no especulativo.- Tal distinción si tiene alguna ventaja carece en cambio de precisión, dada la difusión de la especulación entre el público, especialmente en los momentos de alza de los procios.

Atendiendo al objeto $\mathrm{y}$ al fin, se pueden estudiar rápidamente las diversas operaciones de compra venta al contado..

Las operaciones al contado sobre valores y con fin no especulativo no son muy numerosas en las bolsas, porque resulta más cómodo y fácil hacerlas por intermedio de los bancos, que tienen sus ventanillas abiertas al público.- Las estadisticas que tenemos sobre éstas operaciones son muy satisfactorias $y$ frecuentemente se trata de estadisticas indirectas, obtenidas por medio de los impuestos que las gravan.

Tales operaciones consisten en compra venta de cantidades, en arbitrajes comerciales, es decir'de lugar; de plaza a plaza y de valor; de valor a valor o en combinaciones de las dos especies de operaciones.

Las operaciones al contado sobre valores con, fin especulativo conisisten más frecuentemente en arbitrajes de lugar y de cartera, para encontrar el título más conveniente para hacer pagos sobre determinado mercado; en ventas en previsión de bajas en el valor; o en compras en previsión del alza de los precios.

$Y$ hay que notar que en ciertas bolsas como en la Bolsa de Valores de París existe la costumbre de retardar la entrega de los títulos comprados al contado, desnaturalizando ésta operación.

El contado, permite llevar a efecto una operación que Rotta llama de amontonamiento. - Ella es en si misma muy sencilla y consiste en esto: el poseedor de los títulos pide un préstamo sobre ellos, enseguida adquiere títulos en cántidad menor y vuelve a solicitar un préstamo sobre ellos y así sucesivamente. - Es una especulación al alza, accesible a quien tiene pocos recursos. - Su riesgo se limita a los títulos y la esperanza de ganar se basa en una suma indudablemente mucho mayor.

Las operaciones al contado sobre títulos sufren un diverso tratamiento jurídico y financiero en las bolsas de los diversos países.

Pueden haber operaciones al contado sobre letras, con fines no especulativos, es decir de uso $y$ operaciones al contado sobre letras con 
tin especulativo es, decir de lucro. Consisten en arbitrajes de cambio directo entre dos plazas y de cambio indirecto o compuesto, es decir con el concurso de una o más plazas intermedias.

Para orientarse, el especulador utiliza las tables de paridad y las de cambio, cuyas propiedades, desarrollando las construcciones gráficas de Lefévre, fueron materia de un intesante resumen que aparece en la " $\mathrm{Ri}$ vista dei Raggionirieri", publicada en Padúa en Enero de 1920.

Pueden también hacerse operaciones al contado soibre moneda con fin no especulativo o especulativo $y$ operaciones al contado sobre metales preciosos con fin especulativo o no especulativo, consistentes éstas últimas, sobre todo, en arbitrajes.

Las operaciones al contado sobre mercaderías con fin no especulativo se refieren a la producción 0 al consumo; pueden ser períodicas y referirse también a cantidades no típicas.

Las operaciones al contado sobre mercaderías con fin especulativo se cumplen en vista de ciertos movimientos de la lista es decir del alza o de la baja de los valores, o más raramente con fin de arbitraje.

En Inglaterra el mercado al contado sobre mercaderiłas se desarrrolla en algunas bolsas con la venta voluntaria en pública subasta, previo anuncio de ella en los diarios.

El remate se cumple o con el precio de apertura y las ofertas de aumento o con el precio de apertura alto, que se va rebajando hasta encontrar al comprador. - La aceptación de la oferta del precio y la celebración del contrato son frecuentemente señaladas al público por el consabido golpe de martillo.

En general el comprador tiene la facultad de retirar el lote aun antes de la aceptación de la oferta por parte del mediador. - Concluido el negocio se suele desembolsar el precio en garantía del vendedor y para evitar el incumplimiento del comprador.- En Londres éstos remates se llevan a efecto frecuentemente y sin dificultad alguna. - En la Bolsa de mercaderías de París existe un importante mercado al contado, los días miercoles. - En ese día intervienen numerosos productores de los alrededores con el fin de ofrecer sus productos sobre la base de muestras.

XII.- Operaciones a plazo.- En ellas la ejecución es más o menos diferida. - El momento de la liquidación se encuentra fijado en los. reglamentos de cada bolsa. - El desarrollo de los negocios a plazo puede tomarse como indice del desarrollo del comercio de bolsa.

Las operaciones de compraventa a plazo, slon llamadas por los italianos mercado a plazos, por los franceses futuros y. por los ingleses y alemanes negocios a plazos.

Estas operaciones se diferencian por el objeto, el riesgo y el fin.

Según el objeto las operaciones a plazos pueder. ser de liquida. ción o de emisión.

Las fermas típicas del comercio a plazos en las bolsas sei iniciaron en la República de Genova en el siglo XV, con la contrátación a lar. gos plazos sobre las acciones de la Cámara de San Jorge. - Se la encuentra muy desarrollada en el siglo XVIII en los Países Bajos, con las operaciones sobre cuotas de las Compañías de las Indias Orientales. - Es parte además del sistema Law, que como es sabido se lleva a la práctica en Francia a principios del siglo XVIII.- Aparece también de las prohibiciones en Inglaterra entre los siglos XVII y XVIII entre las cuales es 
típica la ley Barnard de 1733. Se le encuentra también en Alemania en el siglo XVIII - Y se extiende por todos.los países civilizados, con tendencia hacia un régimen jurídico uniforme.

Aun cuando no se dispone de estadísticas precisas, es evidente que el comercio a plazos sobre valores supera, por su volumen, al'comercio al contado.

Se tienen también negocios a plazos sobre valores, monedas y metales preciosos, y productos.

Sobre el comercio a plazos de productos, Kohn recuerda, que la Liga Hanseatica prohibia el comercio del arenque antes de su pesca y de los granos antes de su transformación en harina.

En Holanda, el 6 de Julio de 1928, aparece el primer reglamento del comercio a plazos. - En Inglaterra el comercio de productos en consignación se inicia sobre mercaderías en navegación mientras que el verdadero comercio a plazos sobre algodones $y$ granos se inicia en Liverpool. En Berlin en 1822 se contrata a plazos sobre la avena y la cebada.

En general el desarrollo del comercio a plazos sobre productos es muy reciente.

Las normas que lo rigen son generalmente las mismas que para el comercio de valores, con ligeras disposiciones en más para determinados productos.

Así en la bolsa de mercaderías de París las operaciones a plazo se regulan por reglamentos especiales emanados de los distintos sindicatos: reglamentos que constituyen verdaderos usos del mercado, y que, por lo mismo, tienen valor de ley en ellos.

Segun el riesgo corrido por los contratantes las operaciones a plazos sobre valores o productos pueden ser: operaciones a firme, o sea simples compraventas y compraventas dobles etc, y operaciones a premios o libres, o a opción, es decir compraventas simples, dobles, etc, de opción simple es decir premios directos e indirectos: de opción doble a una base o a dos bases agregadas por el comprador o por el vendedor y combinaciones de compraventa de las tres diversas especies de las que acabamos de hablar; y en fin, combinaciones de las operaciones a firme y de las operaciones a premio.

De éstas combinaciones a firme y de operaciones con premio, como de las combinaciones de las operaciones con premio y de las operaciones a firme entre ellas, pueden resultar operaciones iguales a las ya expuestas y otras que todavia no hemos mencionado.

Sobre las compras y ventas a plazos pueden hacerse arbitrajes: de lugar, es decir de plaza a plaza para el mismo valor y sobre todo para los valores internacionales; de cartera, es decir de valor a valor a plazo sobre las misma plazas o sobre plazas diversas, realizándose arbitrajes mixtos de lugar y de cartera y de operaciones, llegando mediante la combinación más conveniente de diversas operaciones, a la posición que se ha buscado, a la más ventajosa para el comerciante.

Según el fin también las operaciones a plazo se pueden distinguir en dos categorías: operaciones a plazo realizadas con fin no especulativo sobre valores con el objeto de inversión o cambiar la inversión: sobre productojs, por los productores que desean tener anticipadamente la seguridad de vender sus productos: por los comerciantes que quieren tener la seguridad de que sus almacenes estaran, oportunamente abastecidos: co- 
merciantes y productores especulando en estos casos, sin ser especuladores de profesión; y se tienen operaciones a plazo realizadas con fin especulativo, siendo tales operaciones las más aparentes para la especulación profesional es decir para la especulación propiamente dicha. 